\title{
KEGIATAN KONSERVASI LINGKUNGAN DENGAN PELEPASAN RUMPON DI DESA WANASARI KECAMATAN SUNGAI LOBAN
}

\author{
Peri Pitriadi \\ Teknik Perawatan Alat Berat, Politeknik Negeri Ujung Pandang, Indonesia \\ peripitriadisst@gmail.com
}

\begin{abstract}
Success of fishermen in fishing is depend on their knowledge about fish behaviors. Some kind pelagis fish had nature to easily interested \& band togheter around floating object on ocean. Even Tuna fish \& Cakalang often encountered swimming following washed way logs and also sometimes band togheter swims with dolphins, Swordfish, Etc. To make it gather, Rumpon is installed. Rumpon installation activities are carried out with the aim of increasing fishermen production \& productivity because it will make it easier for fishermen to find a place to operate their catching device. Otherwise it will prevent destructive fishing occur, due to use of explosive and chemicals/toxic. This method is done by providing counseling to the surrounding fishing community and releasing 10 Rumpon into the sea. The result of this activity is that fishermen have reference to set catch trap around Rumpons.
\end{abstract}

Keywords : fishermen, fish, Rumpon

\begin{abstract}
Abstrak
Keberhasilan nelayan dalam penangkapan ikan tergantung pada pengetahuan yang cukup mengenai tingkah laku ikan. Beberapa jenis ikan pelagis mempunyai sifat mudah tertarik dan berkumpul di sekitar benda-benda yang terapung di laut. Bahkan ikan tuna dan cakalang sering ditemui berenang-renang mengikuti gelondong-gelondong kayu yang hanyut dan juga kadangkadang bergerombolan bersama-sama dengan ikan lumba-lumba, cucut dan sebagainya. Untuk membuat ikan dapat berkumpul maka dipasang rumpon. Kegiatan pemasangan rumpon ini dilakuakan dengan tujuan meningkatkan produksi dan produktifitas nelayan karena akan memudahkan nelayan menemukan tempat untuk mengoperasikan perangkat tangkapnya. Selain itu akan mencegah terjadinya destruktif fishing, akibat penggunaan bahan peledak dan bahan kimia/beracun. Metode kegiatan ini dilakuakn dengan memberikan penyuluhan ke masyarakat nelayan sekitar dan melakukan pelepasan 10 rumpon ke laut. Hasil dari kegiatan adalah nelayan memiliki acuan untuk memasang perangkap tangkapan di sekitar rumpon.
\end{abstract}

Kata kunci : Nelayan, Ikan, Rumpon.

Submitted: 2020-09-05 $\quad$ Revised: 2020-09-10 $\quad$ Accepted: 2020-09-12

\section{Pendahuluan}

Tingkat keberhasilan suatu usaha penangkapan ikan tergantung pada pengetahuan yang cukup mengenai tingkah laku ikan. Beberapa jenis ikan pelagis mempunyai sifat mudah tertarik dan berkumpul di sekitar benda-benda yang terapung di laut. Bahkan ikan tuna dan cakalang sering ditemui berenang-renang mengikuti gelondong-gelondong kayu yang hanyut dan juga kadang-kadang bergerombolan bersama-sama dengan ikan lumba-lumba, cucut dan sebagainya. Kejadian ini sering kali dimanfaatkan oleh nelayan untuk usaha penangkapan dan selanjutnya digunakan sebagai dasar pengembangan usaha perikanan dengan memanfaatkan benda-benda terapung, para nelayan yang mencari nafkah dengan menggunakan berbagai ragam alat tangkap dan alat bantu penangkapan ikan yang telah dikenal masyarakat nelayan sebagai alat 
pengumpul ikan atau selama ini masyarakat nelayan mengenal salah satunya adalah rumpon.

Rumpon merupakan alat bantu dalam penangkapan ikan. Peraturan Menteri Kelautan dan Perikanan, Nomor PER 02/MEN/2011 mendefinisikan rumpon sebagai alat bantu untuk mengumpulkan ikan dengan menggunakan berbagai jenis atraktor dari benda padat yang berfungsi untuk memikat ikan agar berkumpul. Dengan pemasangan rumpon diharapkan dapat memberikan manfaat kepada nelayan yaitu memudahkan nelayan menemukan tempat untuk mengoperasikan perangkat tangkapnya, mencegah terjadinya destruktif fishing, akibat penggunaan bahan peledak dan bahan kimia/beracun dan meningkatkan produksi dan produktifitas nelayan.

Rumpon atau Fish Aggregating Device (FAD) adalah salah satu jenis alat bantu penangkapan ikan yang dipasang dilaut, baik laut dangkal maupun laut dalam. Pemasangan tersebut dimaksudkan untuk menarik gerombolan ikan agar berkumpul disekitar rumpon, sehingga ikan mudah untuk ditangkap.

Definisi rumpon menurut SK Mentan No. 51/Kpts/IK.250/1/97 adalah alat bantu penangkapan ikan yang dipasang dan ditempatkan pada perairan laut.

Selanjutnya dalam SK Mentan No. 51/Kpts/IK.250/1/97 tentang Pemasangan dan Pemanfaatan rumpon menjelaskan bahwa terdapat 3 jenis rumpon,yaitu:

1. Rumpon Perairan Dasar adalah alat bantu penangkapan ikan yang dipasang dan ditempatkan pada dasar perairan laut

2. Rumpon Perairan Dangkal adalah alat bantu penangkapan ikan yang dipasang dan ditempatkan padaperairan laut dengan kedalaman sampai dengan 200 meter.

3. Rumpon Perairan Dalam adalah alat bantu penangkapan ikan yang dipasang dan ditempatkan pada perairan laut dengan kedalaman di atas 200 meter.

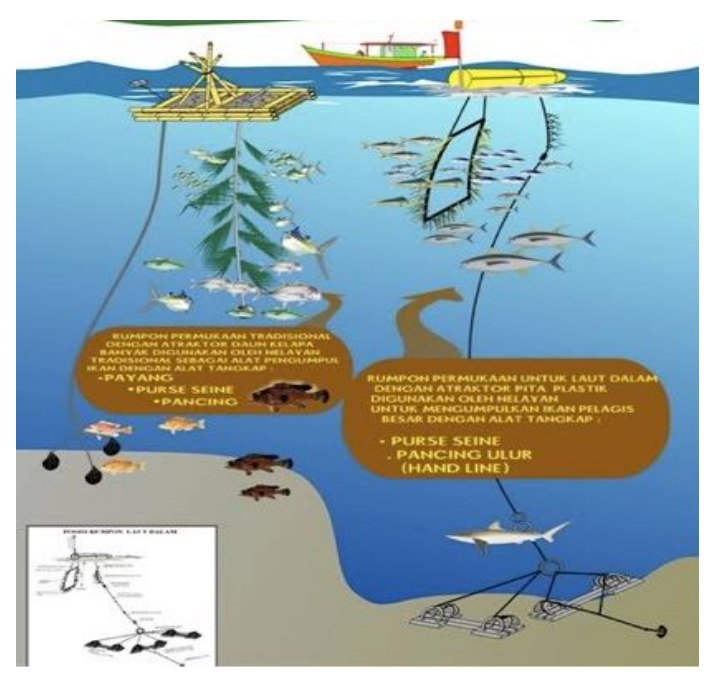

Gambar 1. Rumpon ikan

Beberapa daerah telah banyak mengenal dan menggunakan rumpon permukaan ini, dan nelayan menyebut rumpon tersebut dengan nama tendak (jawa), onjen (JatimMadura), rompong (Sulawesi), gusepa atau "rakit" (Maluku), rebo (Bengkulu). Bentuk dan 
konstruksi rumpon permukaan tradisional ini relatif sederhana dan umumnya terbuat dari bahan alami, seperti :

1. Pelampung terbuat dari bambu berbentuk rakit.

2. Tali jangkar terbuat dari bahan ijuk (untuk nelayan Jawa dan Madura) atau rotan (untuk nelayan Sulawesi). Dewasa ini umumnya sudah menggunakan tali sintetis.

3. Pemikat (atraktor) menggunakan pelepah daun kelapa, lontar, rumbia, dan sebagainya.

4. Pemberat dari batu yang dirangkai menjadi satu serta dilengkapi dengan jangkar dari kayu atau besi.

Namun belakangan ini komponennya sudah banyak diganti dengan bahan sintetis. Rumpon pelagis oleh nelayan Utara Jawa dan Madura dipasang di perairan dangkal dengan kedalaman 40 - 80 meter, sasarannya berupa ikan-ikan pelagis kecil (ikan layang, kembung, selar, lemuru, dan sebagainya), alat tangkap yang digunakan purse seine dan payang. Sedangkan rumpon tradisional nelayan Sulawesi dipasang di perairan laut dalam (kedalaman \pm 500-3000 meter atau lebih). Sasarannya ikan-ikan malalugis, cakalang, tuna sirip kuning / madidihang dan sejenisnya, alat tangkap yang digunakan adalah pancing ulur (hand line), pancing gander (pole and line) dan purse seine (di Sulawesi Utara).

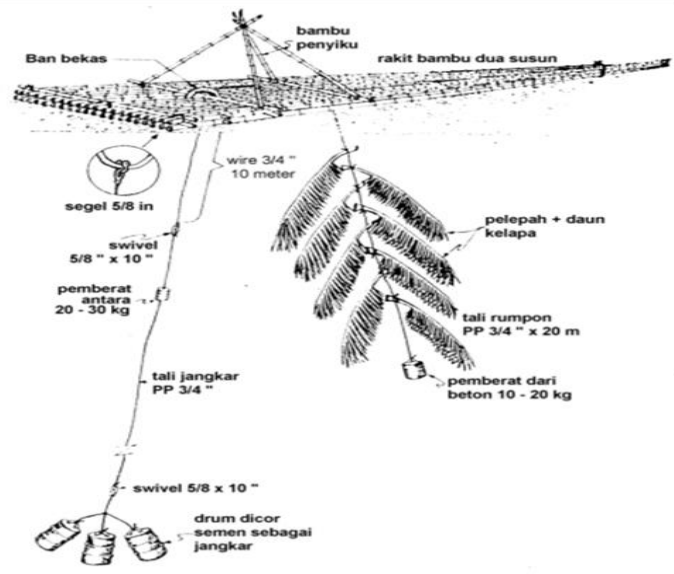

Gambar 2. Konstruksi Rumpon Permukaan Tradisional

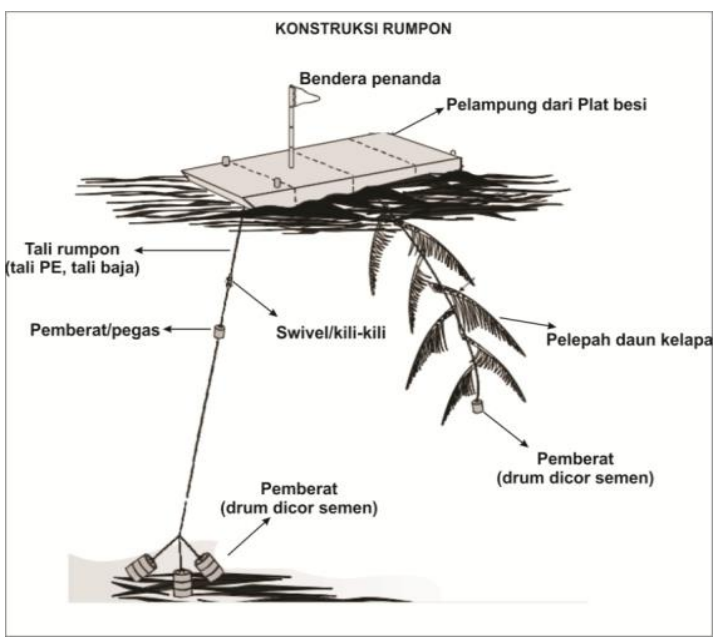

Gambar 3. Konstruksi Rumpon Modern 
Beberapa faktor eksternal yang mempengaruhi keberadaan dan ketahanan rumpon di tengah laut antara lain adalah angin, gelombang dan arus laut. Faktor eksternal tersebut secara teknis harus diperhatikan dan menjadi acuan dalam merancang rumpon pelagis, karena tanpa memperhatikan faktor fenomena oseanografis tersebut maka dapat menjadikan rumpon yang telah terpasang di laut akan mudah hanyut terbawa oleh arus laut, atau talinya akan putus akibat tidak mampu menahan beban yang ditimbulkan oleh faktor eksternal (angin, arus, atau gelombang laut) atau komponenkomponen rumpon yang digunakan terlalu besar ukuran/volumenya sehingga akan menjadikan biaya tinggi.

Arus laut merupakan faktor eksternal yang besar pengaruhnya terhadap unit rumpon pelagis, karena sebagian besar komponennya berada di bawah permukaan laut, dalam hal ini terutama adalah tali jangkar rumpon yang memiliki panjang ratusan bahkan ribuan meter.

\section{Metode}

Pengabdian kepada masyarakat dilaksanakan di pantai madani pada bulan dengan mengundang masyarakat nelayan dari Desa Sungai Loban. Desa yang di pilih untuk melakukan pengabdian masyrakat yang ada di pesisir pantai di kecamatan sungai loban dengan melakukan penyuluhan dan penyerahan rumpon untuk di kelola oleh masyarakat nelayan yang ada di pesisir pantai.

Dalam rangka untuk mencapai tujuan pengabdian masyarakat ini dilakukan langkah-langkah sebagai berikut :

1. Memilih tempat yang akan di jadikan tempat pengabdian ke pada masyarakat serta melakukan dikusi kepada kepala desa untuk berdiskusi dalam pemilihan topik.

2. Meyelenggarakan pelatihan, dengan materi dalam peningkatan pengetahuan dan keterampilan dalam pembuatan produk yang disesuaikan dengan potensi yang ada lingkungan sekitar.

Untuk mencapai keberhasilan dalam kegiatan pengabdian masyarakat ini, maka peserta yang diundang dalam penyuluhan sebanyak 25 orang, dan diadakan serah terima serta pelepasan 10 rumpon ke laut bersama dengan para nelayan.

\section{Hasil dan Pembahasan}

Kegiatan pengabdian masyrakat dilakukan di desa Wanasari Kecamatan Sungai Loban. Rangkaian kegiatan yang dilakukan adalah Sambutan oleh Ketua kegiatan pengabdian masyarakat, Materi tentang rumpon, Serah terima rumpon kepada Kepala Desa dan proses pelepasan rumpon di Laut. 


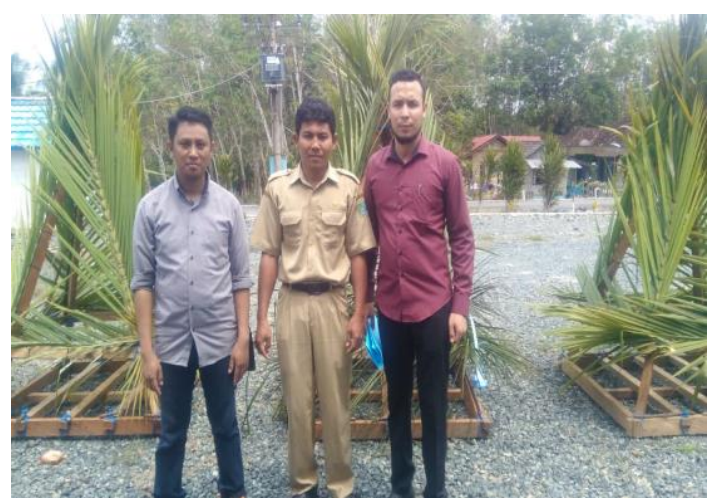

Gambar 4. Serah terima rumpon

Dalam memberikan pemahaman kepada msyarakat sekitar tentang salah satu upaya konservasi lingkungan khususnya pada bidang kelautan maka dilakukan seminar pengenalan rumpon. Seminar ini dibawakan oleh salah satu dosen. Dalam seminarnya memberikan penjelasan dan pengetahuan tentang manfaat rumpon dalam melindungi biota yang ada di laut khususnya yang berada di daerah pesisir.

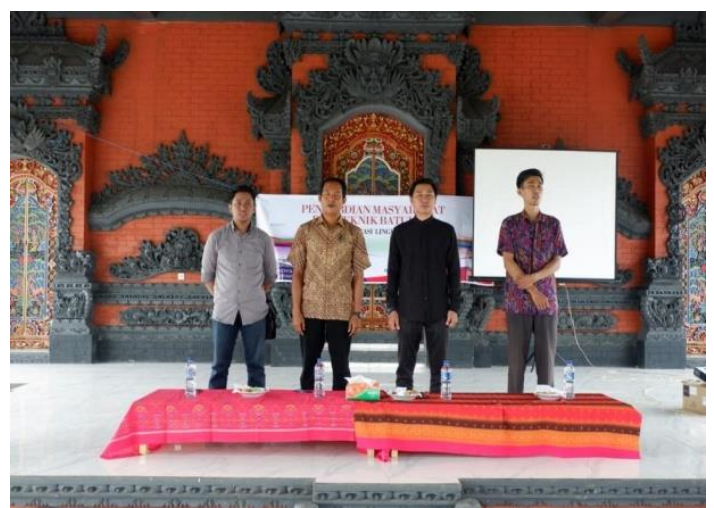

Gambar 5. Seminar pengenalan rumpon

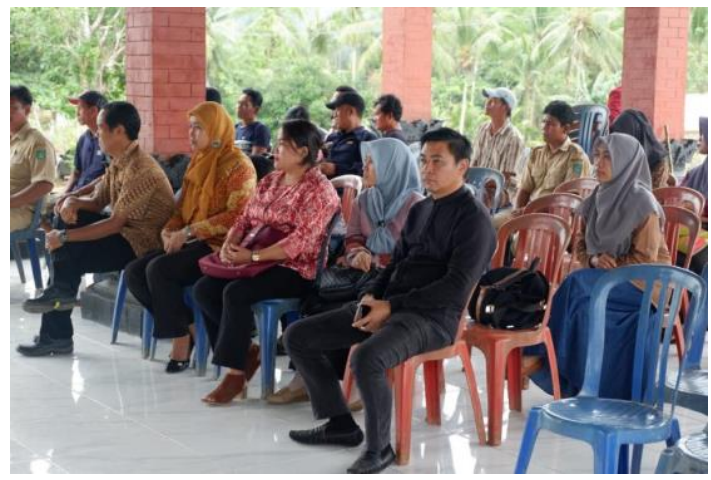

Gambar 6. Peserta Seminar pengenalan rumpon

Serah terima rumpon dilakukan langsung oleh ketua kegiatan pengabdian masyarakat kepada Kepala Desa Wanasari yang dilakukan secara simbolis dan disaksikan masyrakat dan Dosen yang sedang melakukan Pengabdian. Pelepasan rumpon dilakukan langsung oleh masyarakat wanasari dengan meminjam salah satu perahu masyarakat untuk membawa rumpon ke laut. 


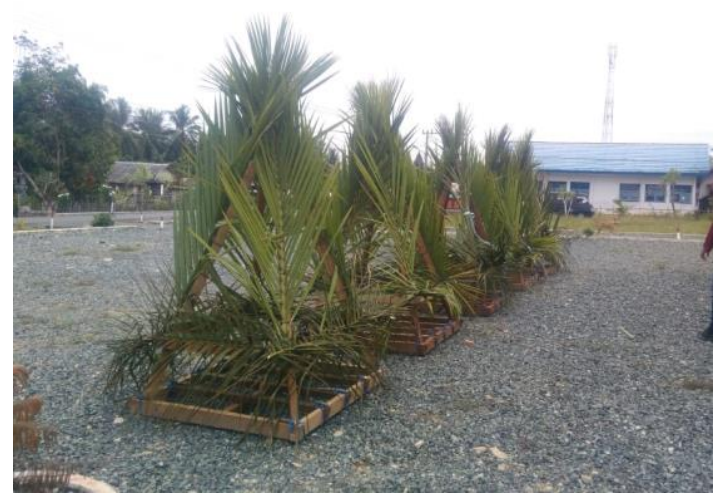

Gambar 7. Rumpon

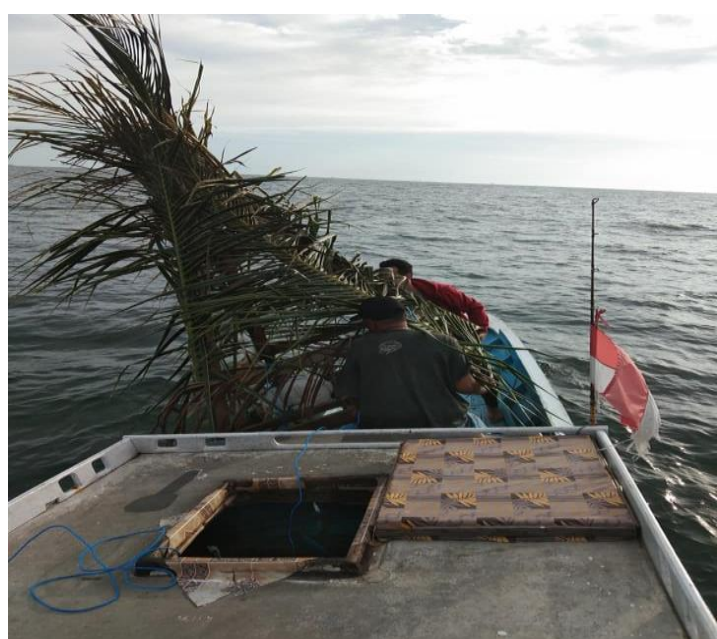

Gambar 7. Pelepasan rumpon di laut

\section{Kesimpulan}

1. Kegiatan ini menjadi wujud penerapan tridarma pendidikan dengan melakukan kegiatan pelepasan rumpon di desa Wanasari . Kegiatan ini berjalan dengan baik dan mendapat sambutan yang dari masyarakat sekitar.

2. Pelepasan Rumpon menjadi wujud kegiatan berkelanjutan yang akan dilakukan dengan warga Desa Wanasari dalam rangka konservasi lingkungan khususnya di bidang Kelautan.

3. Kegiatan ini telah memberikan pemahaman kepada masyrakat tentang manfaat rumpon dan dengan pelepasan rumpon diharapkan mampu menjadi tempat uintuk memasang petrangkap ikan sehingg meningkatkan produksi dan produktifitas nelayan

\section{Daftar Pustaka}

Barus dan Gafa. 1992. Pedoman Teknis Peningkatan Produksi dan Efisiensi melalui Penerapan Teknologi Rumpon. Departemen Pertanian. Badan Penelitian dan Pengembangan Pertanian. Pusat Penelitian dan Pengembangan Perikanan, Jakarta 7 hal. 
Djatikusumo, E.w. 1977. Biologis Ikan Ekonomi Penting. Akademi Usaha Perikanan, Jakarta.

Nursalam dan Pariani (2001). Pendekatan Praktis Metodologi Riset Keperawatan. Jakarta: Sagung Seto.

Subani. (1972). Alat dan Cara penangkapan Ikan di Indonesia Jilid 6. Lembaga Penelitian Perikanan Laut, Jakarta.

Sudirman. (2003). Analisis Tingkah Laku Ikan untuk Mewujudkan Teknologi Ramah Lingkungan Dalam Proses Penangkapan pada bagan Rambo (Tidak dipublikasikan.Disertasi) Program Pasca sarjana Institut Pertanian Bogor. Bogor

Sumardi Zainal. (2009). Teknik Pengoperasian Purse Seine Menggunakan Rumpon Laut Dalam Di Samudera Hindia Bagian Barat Sumatera (Tidak dipublikasikan. Lap. Praktek) Program Diploma 4 PPPPTK Cianjur joint program Politeknik Negeri Jember. Cianjur

Yusfiandayan .dkk. (2014). Konstruksi Dan Produktivitas Rumpon Portable Di Perairan Palabuhanratu, Jawa Barat. Jurnal Teknologi Perikanan dan Kelautan, Bandung. 